\title{
Correction to: Melatonin reduces inflammation in intestinal cells, organoids and intestinal explants
}

\author{
Xi-Zhang $^{1} \cdot$ Xiao-qiang Yuan $^{2} \cdot$ Xueming Zhang $^{1}$ (D)
}

Published online: 8 March 2022

C) Springer Nature Switzerland AG 2022

\section{Correction to: Inflammopharmacology \\ (2021) 29:1555-1564 \\ https://doi.org/10.1007/s10787-021-00869-w}

The last author name has been incorrectly published in the original publication. The complete correct name is given below.

Xueming Zhang

Publisher's Note Springer Nature remains neutral with regard to jurisdictional claims in published maps and institutional affiliations.

The original article can be found online at https://doi.org/10.1007/ s10787-021-00869-w.

Xueming Zhang

zxm1035@163.com

1 Anorectal Surgery, Tangshan Gongren Hospital,

Tangshan 063000, Hebei, China

2 Department of Trauma, Tangshan Gongren Hospital, No. 27,

Wenhua Road, Lubei District, Tangshan 063000, Hebei,

China 